\title{
Effects of Pre-Forming Process and PVC Foam Reinforcement on the Deformation Behavior of Aluminum Tube under Axial Loading
}

\author{
S. Ekşi*, A.O. Kaptiand K. Genel \\ Sakarya University, Mechanical Engineering Department, Sakarya, Turkey
}

\begin{abstract}
In this study, the effects of pre-forming and foam reinforcement on the axial compression behavior of circular thin-walled aluminum tubes were experimentally investigated. Compression tests were performed in a computer controlled test machine at the cross-head speed of $1 \mathrm{~mm} / \mathrm{s}$. Pre-forming has changed the folding behavior of tube and increased the energy absorbing capacity 1.26 times that of empty tube. The PVC reinforcement has increased the energy absorbing capacity 1.22 times. PVC reinforcement increases the stability of tube wall deformation; hence it positively affects the energy absorption. The energy absorbing capacity of pre-formed and PVC foam reinforced tubes increase approximately 1.4 times that of empty tube. It was however shown that the reinforcement and pre-forming had no significant effect on the maximum load.
\end{abstract}

DOI: 10.12693/APhysPolA.132.875

PACS/topics: 81.05.-t, 81.05.Bx, 81.05.Rm, 81.40.Lm, 81.70.-q, 81.05.Pj

\section{Introduction}

The most important properties of thin walled structures are their lightness and considerable high energy absorbing capabilities. Decreasing damage in the course of a crash and precautions taken to control the deformation are essential to maximize the absorbed energy. Thin-walled tubes made of aluminum alloys of high specific strength have been widely investigated in literature [1-16] for determining their crush behavior under axial loading. These alloys are known to have relatively high specific strength and are therefore chosen for applications involving impact loading.

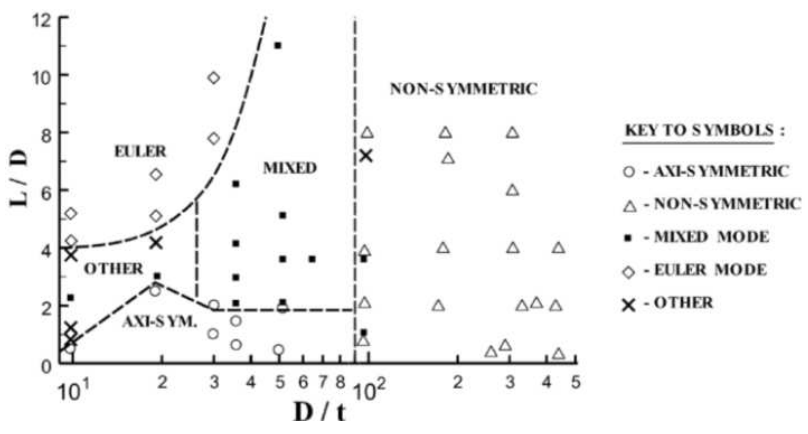

Fig. 1. Mode classification chart for circular 6060-T5 aluminium tubes [1].

There are three types of folding modes in thin-walled tubes under axial loading. These are axisymmetric, nonsymmetric and diamond. The folding mode was also found to be geometry dependent as observed in 6060-T5

*corresponding author; e-mail: eksi@sakarya.edu.tr aluminum tubes, shown in Fig. 1. Folding mechanism changes with $L / D$ ratio, depending on $D / t$ ratio [1].

Alexander et al. [2] investigated the plastic collapse behavior of thin walled metal tube with $D / t$ ratios of 28 and 29. They proposed a model of the symmetric folding mode and deformation behavior [2]. In order to increase the energy absorbing capacity of tubes, one method is to fill the tubes with light-weight foams and honeycombs [3-9]. The combination of tube and filler results in increased specific energy absorption. Heung-Soo [7] has even studied the filling of a real automobile part with foam.

Güden et al. [8] investigated the quasi-static crushing behavior of empty and $\mathrm{Al}$ foam-filled single and two multi-tube designs. It was shown that multi-tube designs were energetically more effective than $\mathrm{Al}$ foam-filled single tubes for both hexagonal and cubic packed designs [8]. Polymer foams were also investigated in literature as reinforcement material in addition to the aluminum foam $[5,11]$.

Davraz et al. studied foam concretes [12]. Many researchers have also done studies on externally fiber reinforced and internally foam filled thin walled tubes, which have high energy absorbing capacity [13-20]. In this study, we have investigated the deformation behavior of PVC-reinforced and pre-formed 6063-T1 aluminum tubes.

\section{Experimental studies}

Thin-walled $\mathrm{Al}$ 6063-T1 tubes were prepared in order to investigate the effect of the pre-forming and PVC foam reinforcement on axi-symetrical compression behavior of such tubes. The outer diameter and wall thickness of cylindrical aluminum tubes were $50 \mathrm{~mm}$ and $1 \mathrm{~mm}$, respectively. The length of tube was chosen to be $60 \mathrm{~mm}$ to induce an axi-symetrical deformation, as seen in Fig. 1. All tube specimens were cut from the same tube. 
Tensile test for the aluminum tube was performed on the specimens prepared according to ASTME8 standard [21]. During the test, strain values were measured by a video extensimeter. Engineering stress-strain curve of the tube material is shown in Fig. 2a. Axial compression load-displacement curve of PVC foam with density of $60 \mathrm{~kg} / \mathrm{mm}^{3}$ is shown in Fig. 2b. The loading rate was kept constant at $1 \mathrm{~mm} / \mathrm{s}$ in all tests. A universal test machine was used.
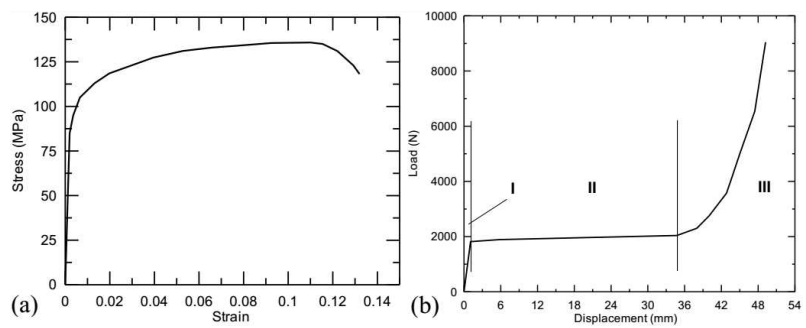

Fig. 2. (a) Tensile stress-strain curve of Al-6063-T1 and (b) the compression load-displacement curve of PVC foam.

The load-displacement curve of PVC foam, shown in Fig. 2b, consists of three distinct regions: linear elastic region (I), plateau region (II) and densification region (III). The plateau stress is an important parameter which determines the level of the load carried by the foam and the homogeneity of carried load. For a high load efficiency, the plateau stress should be nearly constant $[3,6]$. The pictures of the empty and filled tubes with and without channeled sections are shown in Fig. 3.
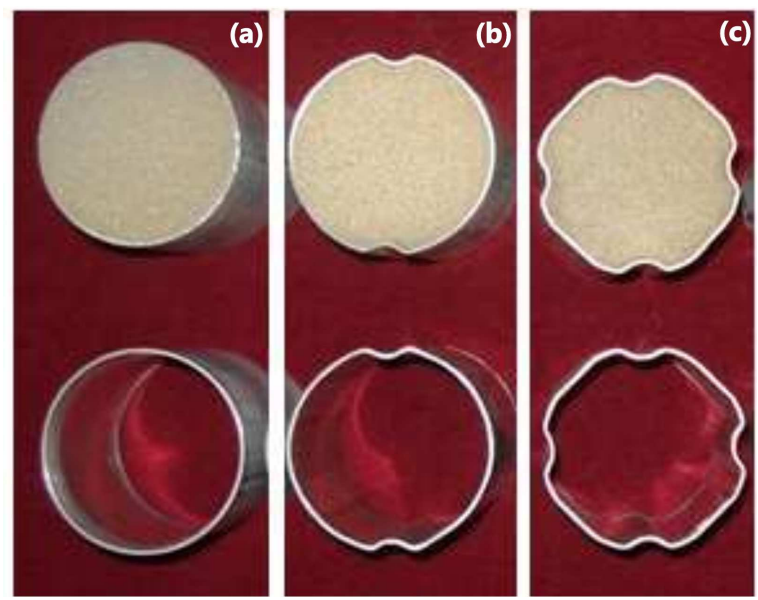

Fig. 3. Test specimens (a) tube and PVC foamreinforced tube, (b) pre-formed tube with two channels and PVC foam-reinforced tube with two channels, (c) pre-formed tube with four channels and PVC foamreinforced tube with four channels.

\section{Experimental results}

Axial compression load-displacement curves of nonreinforced tube is shown in Fig. 4. As noted in this figure, initially the deformation is elastic and the load reaches a maximum, maximum load, at $27.8 \mathrm{~N}$. The first folding or the instability of tube wall starts at that maximum load. As the first fold develops the load decreases from a maximum load to a minimum load, at which a new folding starts to form. Since this deformation mechanism proceeds sequentially, the load values oscillate in the plateau region between a maximum and a minimum load, until about the length of tube is filled with folds. Thereafter, the formed folds are compressed altogether, leading to a sharp increase in the load values. This point is identified as the densification, as seen in Fig. 4. The pictures of empty non-deformed and deformed tube are shown in Fig. 5a. As seen in this figure, the tube is deformed in symmetric folding mode, as projected from Fig. 1. Although, the symmetric folding is dominant in empty tubes, some tubes deform in diamond mode, resulting from variations in the discontinuity in tube wall, as seen in Fig. 5b.

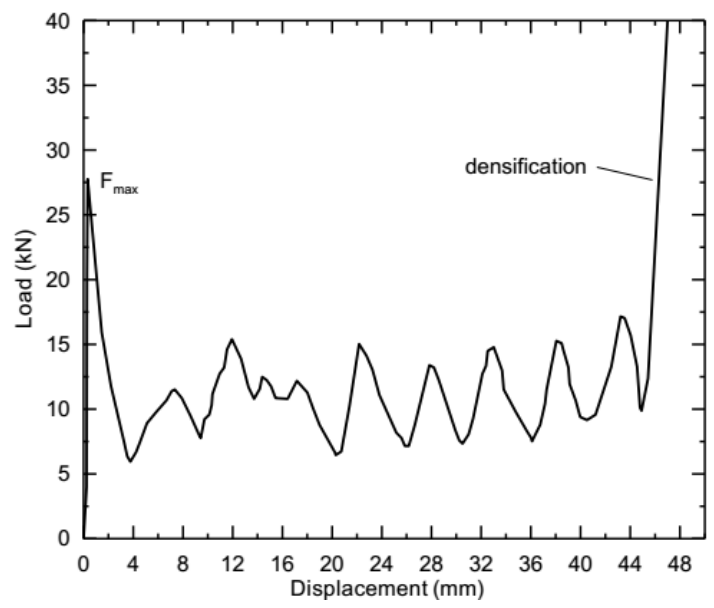

Fig. 4. Load-displacement curve of aluminum tube.
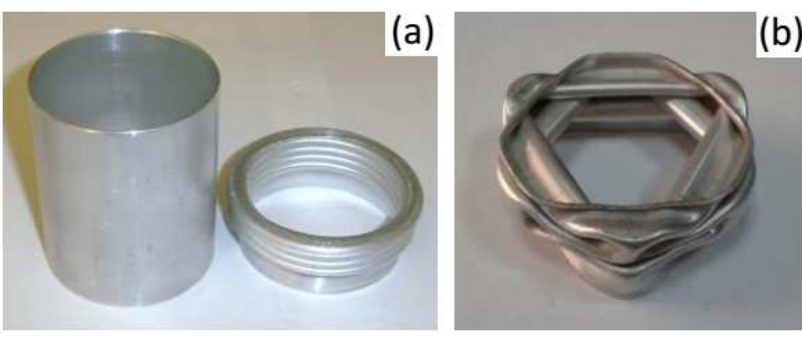

Fig. 5. (a) View of the aluminum tube before and after the test and (b) diamond type folding.

The load-displacement curve of PVC foam-filled aluminum tube is shown in Fig. 6. Although PVC reinforcement has increased the energy absorbing capacity of the tube, it has almost no effect of the maximum load, as it has a relatively crushing stress. However, PVC foam increases the energy absorbing capacity of empty tube by a factor of 1.2. It also increases the mean load by $17 \%$. It is noted that the sum of mean load of PVC foam and 
aluminum tube alone is lower than that of PVC reinforced tube. This effect is known as the interaction effect in literature and the relative increase in the load of filled tube over the empty tube was attributed to the restrictive effect of PVC foam to the tube wall folding $[5,10]$.

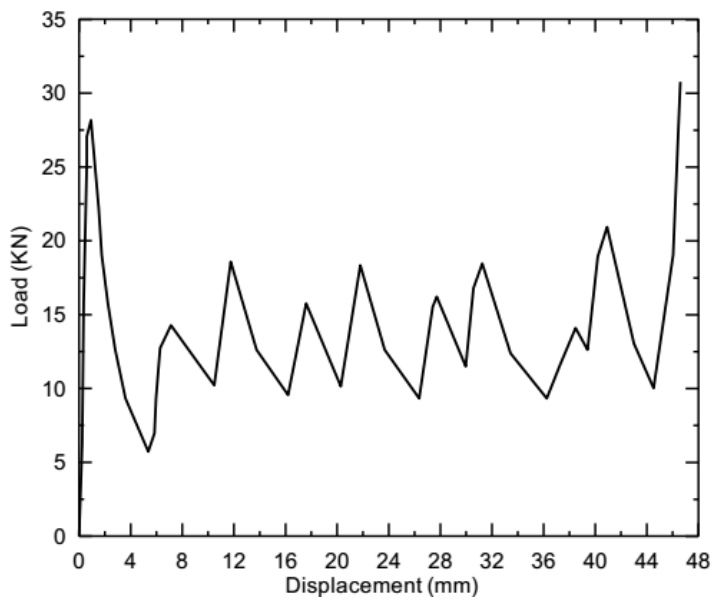

Fig. 6. Load-displacement curve of PVC foamreinforced aluminum tube.

The load-displacement curves of two-channeled aluminum tube and PVC foam reinforced two-channeled aluminum tube are shown in Fig. 7. The folding of these tubes is found to be not homogeneous. The load carrying and energy absorbing capacity of two-channeled aluminum tube do not increase significantly and these tubes show diamond mode of folding. The energy absorbing capacity of tube with reinforcing PVC increases 1.32 times over the empty tubes. The mean load values increase to $14 \mathrm{kN}$. The load-displacement curves of four-channeled aluminum tube and PVC foam-reinforced four-channeled aluminum tube are shown in Fig. 8.
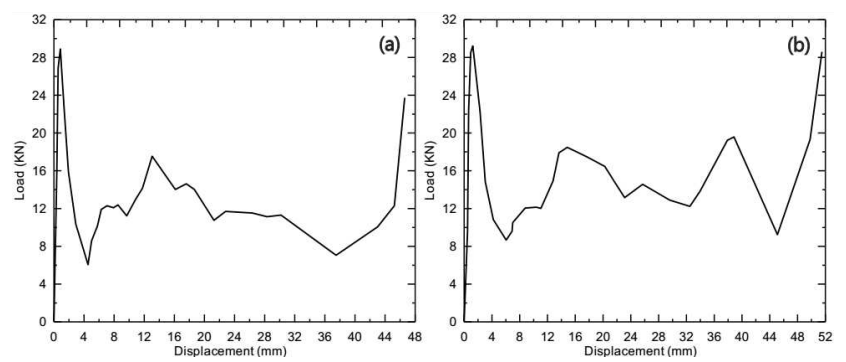

Fig. 7. (a) Load-displacement curve of two-channeled aluminum tube, (b) load-displacement curve of PVC foam-reinforced two-channeled aluminum tube.

The pre-formed tubes display diamond-like irregular folding. Energy absorbing capacity increases 1.26 times. Pre-formed and PVC-reinforced aluminum tube show a diamond like irregular folding too. PVC reinforcement increases the energy absorbing capacity 1.4 times with increasing folding resistance. This can be explained by the increase of the mean load values with pre-forming of
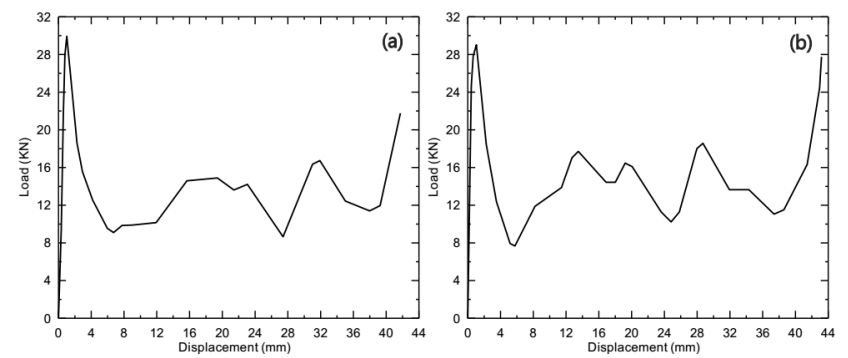

Fig. 8. (a) Load-displacement curve of four-channeled aluminum tube, (b) load-displacement curve of PVC foam-reinforced four-channeled aluminum tube.

a tube. Increasing hardness and yield strength of strained hardened material increases mean load with remaining folding resistance during compression, as expected. Hardness measurement on a deformed tube region has shown that hardness is increased by $5-7 \mathrm{HV}$. The results obtained from the test are given in Table I.

TABLE I

Result of compression tests.

\begin{tabular}{c|c|c|c|c|c}
\hline \hline $\begin{array}{c}\text { Specimen } \\
(*)\end{array}$ & $\begin{array}{c}\text { Maximum } \\
\text { load }[\mathrm{kN}]\end{array}$ & $\begin{array}{c}\text { Mean load } \\
{[\mathrm{kN}]}\end{array}$ & $\begin{array}{c}\text { Energy } \\
{[\mathrm{J}]}\end{array}$ & $\begin{array}{c}F_{\text {maks }} \\
\text { ratio }\end{array}$ & $\begin{array}{c}\text { Energy } \\
\text { ratio }\end{array}$ \\
\hline $\mathrm{PVC}$ & 2 & 2 & 97 & 0.07 & 0.19 \\
$\mathrm{~T}$ & 27.8 & 11.5 & 506 & 1.00 & 1.00 \\
$\mathrm{~T}+\mathrm{PVC}$ & 28.2 & 13.5 & 618 & 1.01 & 1.22 \\
$\mathrm{~T}(2)$ & 28.9 & 11.75 & 527 & 1.04 & 1.04 \\
$\mathrm{~T}(2)+\mathrm{PVC}$ & 29.2 & 14 & 666 & 1.05 & 1.32 \\
$\mathrm{~T}(4)$ & 29.9 & 12.5 & 640 & 1.08 & 1.26 \\
$\mathrm{~T}(4)+\mathrm{PVC}$ & 29.02 & 13.1 & 684 & 1.04 & 1.4 \\
\hline
\end{tabular}

* Energy value is calculated until $45 \mathrm{~mm}$ displacement,

$(*)$ : channel number.

It is clearly seen from the table that energy value tends to increase proportionally to load value. It is also observed that deformation behavior of channel-formed aluminum tube is completely changed, however energy absorbing capability gets better with respect to non-deformed structure. It is possible to say that in the pre-formed tube the enhancement of the bending inertia, as well as the hardness, delay folding process. Views of specimens after the compression test are given in Fig. 9.

\section{Conclusions}

The following conclusions were drawn based on the experimental investigations of empty and filled nonchanneled and channeled tubes.

- In PVC-reinforced tube the energy absorbing capacity is increased 1.22 times, due to increasing wall stability of the tube, whereas pre-forming process increases the energy absorbing capacity of tube 1.26 times. 

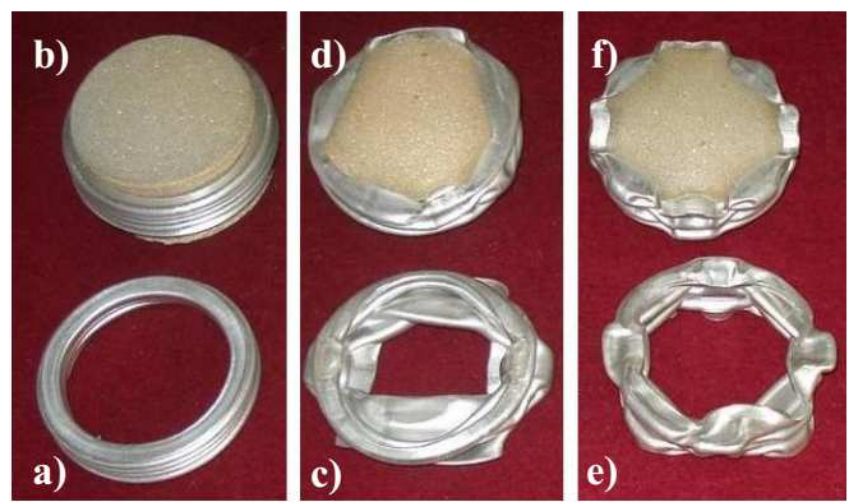

Fig. 9. View of specimens after axial compression tests (a) $\mathrm{T}$, (b) T+PVC, (c) T(2), (d) T(2)+PVC, (e) T(4), (f) $\mathrm{T}(4)+\mathrm{PVC}$.

- Energy absorbing capacity of pre-formed tube with reinforced PVC foam is increased 1.4 times, with respect to the non-reinforced tube. On the other hand, this causes no significant effect on maximum load capacity in PVC foam-reinforced structures.

\section{Acknowledgments}

This work was supported by TUBITAK (The Scientific and Technological Research Council of Turkey) under project number $115 \mathrm{M} 583$.

\section{References}

[1] S.R. Guillow, G. Lu, R.H. Grzebieta, Int. J. Mech. Sci. 43, 2103 (2001).

[2] J.M. Alexander, Quart. J. Mech. Appl. Math. 13, 5 (1960).
[3] S.P. Santosa, T. Wierzbicki, A.G. Hanssen, M. Langseth, Int. J. Impact Engin. 24, 509 (2000).

[4] A.G. Hanssen, O.S. Hopperstad, M. Langseth, Int. J. Crashworthiness 6, 177 (2001).

[5] M. Güden, A.K. Toksoy, H. Kavi, J. Mater. Sci. 41, 6417 (2006)

[6] M. Seitzberger, F.G. Rammerstorfer, R. Gradinger, H.P. Degischer, M. Blaimschein, C. Walch, Int. J. Solids Struct. 37, 4125 (2000).

[7] K. Heung-Soo, Int. J. Crashworthiness 6, 189 (2001).

[8] M. Güden, H. Kavia, Thin-Walled Struct. 44, 739 (2006).

[9] I.W. Hall, M. Güden, T.D. Claar, Scripta Materialia 46, 513 (2002).

[10] L. Aktay, A.K. Toksoy, M. Güden, Mater. Design 27, 556 (2006).

[11] J.M. Babbage, P.K. Mallick, Composite Struct. 70, 177 (2005).

[12] M. Davraz, Ş. Kilinçarslan, M. Koru, F. Tuzlak, Acta Phys. Pol. A 130, 469 (2016).

[13] M.R. Bambach, Thin-Walled Struct. 48, 440 (2010).

[14] M.R. Bambach, H.H. Jama, M. Elchalakani, ThinWalled Struct. 47, 1112 (2009).

[15] C.S. Cha, K.S. Lee, S.H. Kim, J.O. Chung, I.Y. Yang, Key Engin. Mater. 297, 166 (2005).

[16] K.C. Shin, J.J. Lee, K.H. Kim, M.C. Song, J.S. Huh, Composite Struct. 57, 279 (2002).

[17] K.H. Kim, K.C. Shin, J.J. Lee, Key Engin. Mater. 183, 1147 (2000).

[18] S. Ekşi, K. Genel, Acta Phys. Pol. A 128, B-59 (2015).

[19] G.I. Sezer, S. Yazıcı, A. Sezer, Acta Phys. Pol. A 128, B-37 (2015).

[20] I.K. Yilmazcoban, S. Doner, Acta Phys. Pol. A 130 , 342 (2016).

[21] ASTM E8/E8M standard test methods for tension testing of metallic materials. 